\title{
Sintering by infiltration of loose mixture of powders, a method for metal matrix composite elaboration
}

\author{
V. CONSTANTINESCU, R. ORBAN and H. COLAN
}

Technical University of Cluj-Napoca, Faculty of Materials Science and Materials Engineering, Department of Materials Science and Materials Technology, Str. C. Daicoviciu 15, 3400 Cluj-Napoca, Romania

\begin{abstract}
starting from the observation that sintering by Infiltration of Loose Mixture of Powders confers large possibilities for both complex shaped and of large dimensions Particulate Reinforced Metal Matrix Composite components elaboration, its mechanism comparative with those of the classical melt infiltration was investigated. Appropriate measures in order to prevent an excessive hydrostatic flow of the melt and, consequently, reinforcement particle dispersion, as well as to promote wetting in both infiltration and liquid phase sintering stages of the process were established as necessary.

Some experimental results in the method application to the fusion tungsten carbide and diamond reinforced metal matrix composite elaboration are, also, presented.
\end{abstract}

\section{Introduction}

The remarkable development in the last few years of the particulate Reinforced Metal Matrix Composite (PRMMC) applications has determined a corresponding progress in their manufacturing methods [1],[2]. An overview on this methods puts into evidence the tendency to combine PM with liquid based routes, as in co-spray deposition method [1], in order to eliminate their opposite limitations.

Sintering by Infiltration of Loose Powders (SILP) is too a combination between $P M$ and Liquid based methods, but can be realised at a less cost than co-spray deposition, using a common, chipper, equipment. It consists (fig.1) in an adequate shaped mould cavity 1 filling with a selected mixture of powders 2 , followed by its infiltration with an appropriate molten alloy 3 placed into a funnel 4 , at the top or at the bottom of the mould
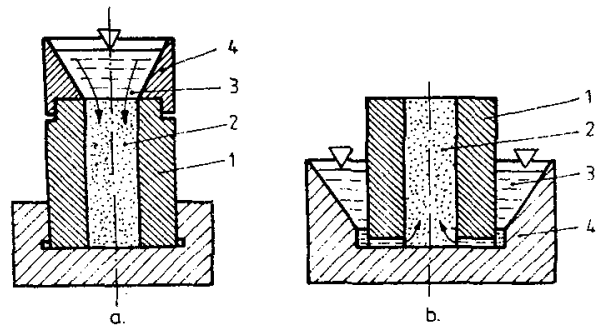

Fig.1. Scheme of the SILP process cavity. This infiltrating alloy must to be able to act as a liquid phase and sinter together, by a liquid phase sintering process, the 
powder particles. The new in this way formed alloy must to have appropriate properties for acting as a metal matrix. It shall to incorporate, by a simple mechanical enclosure or by diffusional liaisons, the non-metallic components comprised in powder mixture or, depending on the followed aim, only inserted in the mould walls. So, after cooling, a PRMMC of both geometrical shape and dimensions determined by the mould cavity results.

Although the SILP method have been applied to structural parts fabrication [3], it seems it has not been yet sanctioned as a method\& for PRMMC or common PM parts elaboration [1],[2],[4]. This is the reason of the investigations presented in this paper, having as end to elucidate the basic SILP phenomena and their influencing factors.

\section{Experimental conditions}

From the above brief description results that, at a first view, the SILP process has two similar stages as the extensively documented melt infiltration of presintered powder compacts: infiltration and liquid phase sintering [1] . Consequently, appropriate conditions for studding of the particularities of these stages occurring in the case of loose powder skeleton ware chosen. So, adequate loose mixtures of powders and infiltrating alloys for different investigations ware selected (tab.1). These will be presented in correlation with their destinations. All

Table 1. Compositions of used loose mixtures of powders and infiltrating alloys

\begin{tabular}{|c|c|c|c|c|c|c|c|c|}
\hline Material & Components & c & o & $\mathbf{n}$ & $\mathbf{t}$ & $\mathbf{e}$ & $\mathbf{n}$ & $t$, \\
\hline \multirow{4}{*}{$\begin{array}{l}\text { Powder } \\
\text { mixture }\end{array}$} & Symbol & $\mathrm{PM}_{1}$ & $\mathbf{P K}_{2}$ & $\mathrm{PM}_{3}$ & $\mathbf{P M}_{4}$ & $\mathbf{P M}_{5}$ & $\mathbf{P M}_{2}$ & $\mathbf{P M}_{3}$ \\
\hline & $W_{2} C+W C$ (fus) & - & & 84 & 72 & 89 & - & 84 \\
\hline & $\mathrm{w}$ & 100 & 86 & - & 23 & 5 & 86 & - \\
\hline & $\mathrm{Ni}$ & - & 14 & 16 & 5 & 6 & 14 & 16 \\
\hline \multirow{7}{*}{$\begin{array}{l}\text { Infiltrating } \\
\text { alloy }\end{array}$} & Symbol & $I_{1}$ & \multicolumn{2}{|r|}{$\mathrm{I}_{2}$} & \multicolumn{2}{|r|}{$I_{3}$} & \multicolumn{2}{|r|}{$I_{4}$} \\
\hline & $\mathrm{Cu}$ & 100 & \multicolumn{2}{|r|}{79} & \multicolumn{2}{|r|}{75} & \multicolumn{2}{|r|}{71.5} \\
\hline & sn & - & \multicolumn{2}{|r|}{14} & \multicolumn{2}{|r|}{6} & \multicolumn{2}{|r|}{ - } \\
\hline & $\mathrm{Ni}$ & - & & - & & 10 & \multicolumn{2}{|r|}{ - } \\
\hline & $\mathrm{zn}$ & - & \multicolumn{2}{|r|}{ - } & \multicolumn{2}{|r|}{ - } & \multicolumn{2}{|r|}{25} \\
\hline & si & - & \multicolumn{2}{|r|}{1} & \multicolumn{2}{|r|}{1} & \multicolumn{2}{|r|}{3.5} \\
\hline & Fe-Mn(Mo) & - & \multicolumn{2}{|r|}{ Bal. } & \multicolumn{2}{|r|}{ Bal. } & \multicolumn{2}{|r|}{ Bal. } \\
\hline Diamond & Type & - & \multicolumn{2}{|r|}{ Nat. } & \multicolumn{2}{|r|}{ Nat. } & \multicolumn{2}{|r|}{ syn. } \\
\hline
\end{tabular}

experiments ware made using graphite moulds of appropriate shape cavities in order to obtain the necessary kinds of samples. In all cases, the infiltrating alloy was added, in a granular solid state, into the mould funnel. The processes ware carried out into a room electrical heated furnace, under nitrogen as protective atmosphere, at temperatures of $1200^{\circ} \mathrm{C}$ for $I_{1}$ and $I_{3}, 1150^{\circ} \mathrm{C}$ for $I_{2}$ and $1050^{\circ} \mathrm{C}$ for $I_{4}$. standard duration was of 20 minutes. 


\section{Investigations on the infiltration of loose powders mechanisms}

In the melt infiltration of the presintered powder compacts, the infiltration mechanism is mostly based on the action of capillary forces. Infiltration rate is inverse related to both surface tension of the new formed liquid/solid interface $\tau_{L S}$ and capillary radius [1].

Unlike of this, the unbounded particles of the loose powder doesn't constitute a rigid skeleton of a unique solid phase. As a consequence, both capillary radius and liquid/solid surface tension can to vary during the liquid phase penetration into the interparticular channels, determining the predominance of the capillary or hydrostatic flow infiltrating mechanism.

In order to establish to what extent the average interparticular channels radius variation can be effective, the variation of the proper loose powder skeleton porosity during infiltration for a system without mutual solubility, containing a unique solid phase $\left(\mathrm{PM}_{1}-\mathrm{I}_{1}\right)$, was found as appropriate. Indeed, if only capillary infiltrating mechanism occurs, the porosity must to slowly decrease or remain constant [4] on the contrary, a porosity increasing demonstrates a net hydrostatic flow which moves powder particles from one another. Figure 2 briefly shows results of this study. At a very low heating rate (1), the system porosity is near constant maintained during infiltration, independent by initial loose powder porosity and particle size. This shows that, when infiltrant gradually melts, the infiltration process of loose powders almost exclusively occurs by capillary phenomena. By increasing heating rate $(2 \ldots 4)$, the solid infiltrant melts faster and exerts a hydrostatic pressure on the particles, moving them from one another. So, the predominant infiltrating mechanism becomes hydrostatic flow. Its importance is as high as the loose powder porosity is higher and powder particles are finer, giving raise to a low density of the reinforcement component in metal matrix (fig.3-a). However, at a sufficiently low porosity and appropriate grain size distribution, predominant mechanism remains the capillary flow, relative porosity variation being near

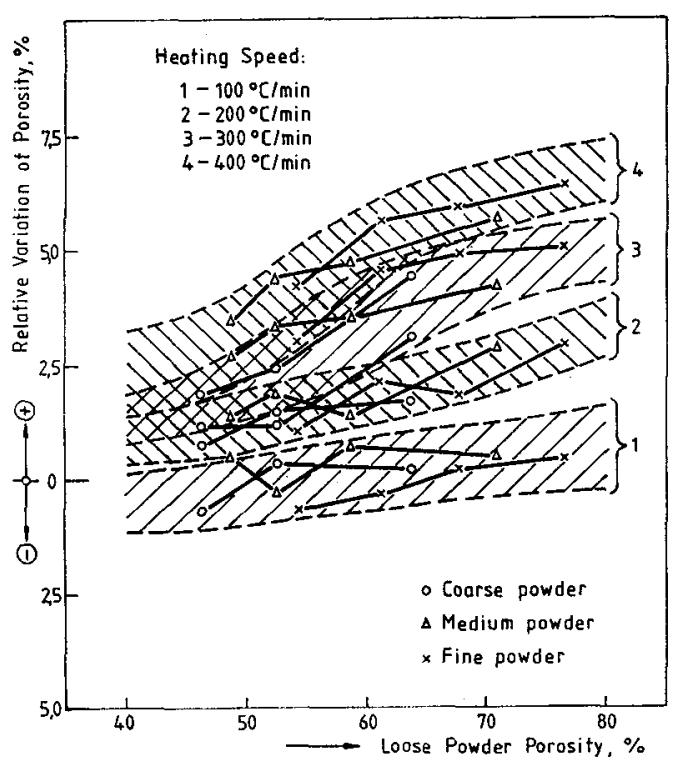

Fig.2. Loose powder porosity and particle size influence on the skeleton porosity variation during infiltration zero.

The second influencing factor, liquid/solid surface tension variation, is determined by the successive contacts of flowing liquid phase with different kinds of particles from powder mixture. Although some hydrophobe particles can have the tendency to stop capillary flow, it is more than likely that another neighbouring hydrophile particles counteract this tendency and promote capillary flow. 
Certainly, in order to obtain a dense and uniform distribution of the reinforcement component, it is necessary to assure conditions for almost all infiltrating process occurring by capillary flow. Beside of

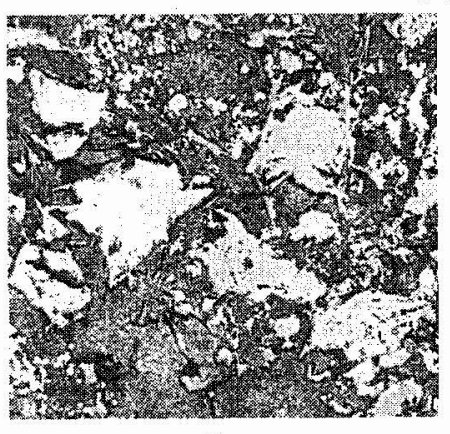

a

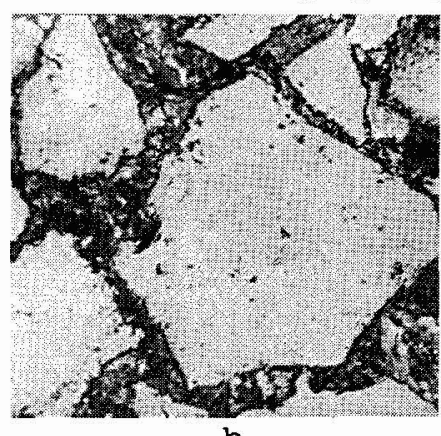

b

above mentioned optimum porosity, wetting of the all kinds of particles from powder mixture by the liquid infiltrant must be promoted. Wetting is effected between a solid particle surface and liquid infiltrant when the strength of the interfacial bond exceeds the surface tension of the liquid, $\quad \tau_{\mathrm{sv}}{ }^{-\tau_{\mathrm{LS}}}>\tau_{\mathrm{LV}}$. This strength is, in fact, the driving force of the liquid capillary flow and depends upon the both $\tau_{\mathrm{Sv}}$ and $\tau_{\mathrm{LV}}$ surface tensions of the solid powder particles and of the liquid infiltrant, as well as upon the $\tau_{\text {Ls }}$ surface tension of the new formed liquid/solid interface. Consequently, although the "infiltrability" is often considered as a property of the molten infiltrating alloy, in fact it is a complex property of the molten infiltrating alloy - loose mixture of powder - infiltrating atmosphere system. Its increasing is, therefore, possible by: a) acting in order to promote wetting by interfacial tension $\tau_{\text {Ls }}$ lowering using fluxes as detergents as well as by liquid-vapour tension $\tau_{\text {Lv }}$ decreasing using appropriate alloying elements of the infiltrant such as Li, Si, Zn a.o. [5] or vapour forming surfactants mixed with the loose powder [6]; b) acting for an optimum porosity of the loose powder by an adequate particle size and size distribution chose or by its vibratory densification into the mould cavity. Figure 3-b shows the micrograph of a $\mathrm{PM}_{3}-\mathrm{I}_{2}$ sample obtained in these conditions.

\section{Approach to liquid phase sintering stage of the SILP process}

The above mentioned characteristics of the loose powders skeleton can determine some particularities in the well known stages of its liquid Phase sintering Process $[1],[4],[6]$.

\subsection{Re-arrangement of the powder particles}

The solid phase densification prior to liquid phase forming, which is present in the classical LPS, certainly, can't to appear. consequently, the re-arrangement of the powder particles constitutes the first stage of the loose powder LPS, driving force being a net decrease in the system energy by changes in the areas of the liquid/vapour, liquid/solid and solid/vapour interfaces [4], [5].

However, while in the classical processes, the amount of liquid phase is relatively small, in the loose powder sintering it is usually in excess. Consequently, under both the surface tensions and Archimedic forces, at the top of the mould cavity powder particles can to be brought in a suspension state into the melt. The hardness decreasing to the top of a cylindrical sample processed in a vertical position, especially when fine loose powder was used, has proved this supposed 
phenomenon (fig.4). The necessity of an appropriate amount of infiltrating alloy utilisation, corresponding to the loose powder porosity, results. In this case, the re-arrangement process gives rise to an uniform, dense, distribution of the reinforcement component (see fig.3-b).

\subsection{Solution - dissolution stage}

In the SILD process, solution dissolution phenomena should to form the proper metal matrix alloy with certain imposed properties. For this purpose, both loose powder mixture and infiltrating alloy must to be appropriate selected. So, for exemplification, if loose powder contains a tungsten - nickel mixture $\left(\mathrm{PM}_{2}\right)$ and infiltrant is a cooper based alloy $\left(I_{2}\right)$, a heavy alloy of a fine microstructure (fig.5-a) and high mechanical properties is formed.

As an important particularity must to be mentioned the reinforcement
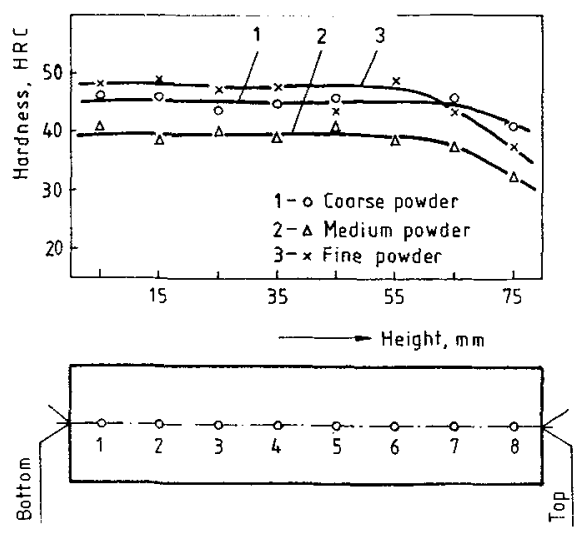

Fig.4. Hardness variation along a SILP sample processed in vertical position components presence. If they have a limited solubility with new formed metal matrix, a diffusional bind will give rise. In figure 5-b is presented a such bind for a fusion tungsten carbide particle in a nickel based metal matrix $\left(\mathrm{PM}_{2}-\mathrm{I}_{2}\right)$. It is to be observed the transition layer with a gradual variation of dimensions of the micro-hardness imprints. On the contrary, if there is any solubility between reinforcement components and metal matrix, a mechanical enclosure must to form. This also impose a good wetting, the work of adhesion being inverse related with the liquid/solid surface tension. In this stage of the SILD process, it can be improved only by small additions of some active elements ( $\mathrm{Li}, \mathrm{Al}, \mathrm{Si}, \mathrm{Zn}$ a.o.) in infiltrating alloy [5]. Also, processing conditions must to give not rise to secondary interface reactions or to another effects which can affect the integrity of the reinforcement components [5]. So, for exemplification, the natural diamond using as reinforcement component supports processing temperatures of about $1150-1200^{\circ} \mathrm{C}$ which are necessary when $\mathrm{Cu}-\mathrm{Sn}$ and $\mathrm{Cu}-\mathrm{Sn}-\mathrm{Ni}$ based $\left(\mathrm{I}_{2}, I_{3}\right)$ infiltrating alloys are used [3]. On the contrary, synthetic diamond, having a less thermochemical stability [2], imposes processing temperature below of about $1100^{\circ} \mathrm{C}$. So, another kind of infiltrating alloy $\left(\mathrm{Cu}-\mathrm{Zn}-\mathrm{Si}, \mathrm{I}_{4}\right)$ was found as necessary [7] . Figure 5-c presents a quite perfect enclosure of a such synthetic diamond grain in an $\mathrm{PM}_{2}-\mathrm{I}_{4}$ metal matrix.

\subsection{Final, solid phase sintering stage}

In the case of loose powders, occurs during the mould cooling after heat treating. Consequently, an uniform cooling rate is necessary.

\section{Conclusions}

The above presented results have obviously demonstrated there are essential differences in both infiltration and liquid phase sintering stages of the SILD process in respect with those of the classical melt infiltration of presintered compacts. Appropriate measures to prevent 


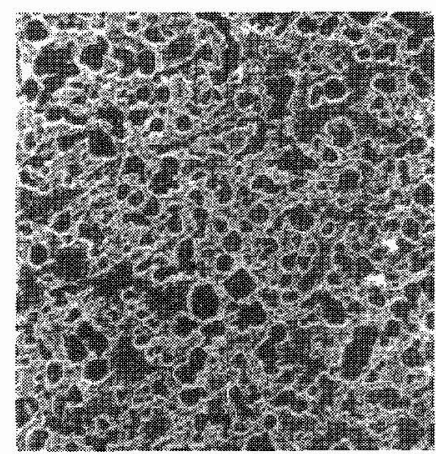

a

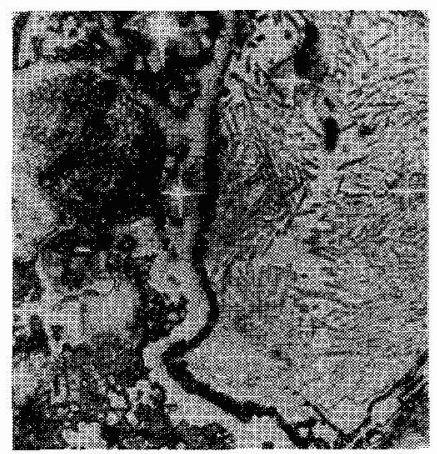

$\mathrm{b}$

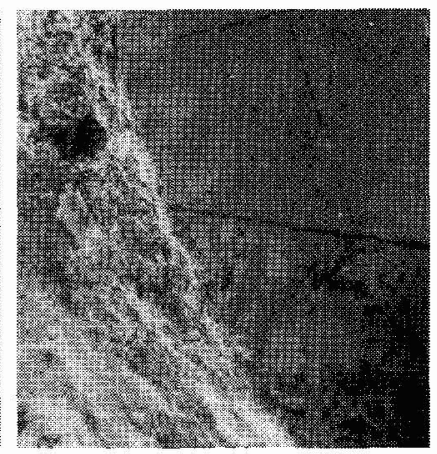

C

Fig.5. a) $\mathrm{PM}_{2}-\mathrm{I}_{2}$ heavy alloy $\mathrm{MM}\{200: 1\}$; b) $W C / \mathrm{PM}_{3}-\mathrm{I}_{2} \mathrm{MM}\{400: 1\}$; c) Synthetic diamond grain/PM $4-I_{4}\{2000: 1\}$

an excessive hydrostatic flow of the melt as well as to promote wetting ware established as necessary. In order to prove the efficiency of these measures, the SILP method was applied to $\mathrm{PM}_{3}, \mathrm{PM}_{4}-\mathrm{I}_{3}$ fusion tungsten carbide and diamond reinforced MMC for drilling tools elaboration. In table 3 are presented the principal mechanical

Table 2. Mechanical properties of some fusion Tungsten Carbide and Diamond PRMMC elaborated by the SILP method

\begin{tabular}{|c|rr|r|c|}
\hline Naterial type & \multicolumn{2}{|c|}{ Fracture strength } & Hardness & $\begin{array}{c}\text { Wear re- } \\
\text { sistance } \\
\text { J/mm }\end{array}$ \\
\hline Compression & Hield & HRC & 6740 \\
\hline WC-W-Ni-Cu-Zn & $640-1030$ & $340-590$ & $36-49$ & 7870 \\
\hline
\end{tabular}

properties of the obtained PRMMC, which have assured high operational characteristics of the manufactured drilling tools.

\section{References}

1. X X X Metals Handbook. Ninth-Edition, vol.7-Powder Metallurgy. ASM, USA, 1984.

2. Feest, E.A. a.o. - Powder Metallurgy Composites. Powder Metallurgy - an Overview, Ed. I.Jenkins and J.V.Wood, The Institute of Metals, ENGLAND, 1991, p.267-286.

3. Constantinescu,V., Orban,R. a.o. - Properties of some wear resistant special sintered materials. P/M' 86 I.P.M.C. Horizons of Powder Metallurgy, p.575-578.

4. Kaysser,W.A. - Liquid Phase Sintering. Powder Metallurgy - an Overview, Ed. I.Jenkins and J.V.Wood, The Institute of Metals, ENGLAND, 1991, p.183-197.

5. Gupta a.o. - Wetting and interfacial reactions in Al-Li-SiC metal matrix composites... Journal of Materials science, 26 (1991), p.6673-6686.

6. Terry,B.S., Chinyamakobvn,o.s. - Dispersion and reaction of TiC in liquid iron alloys. Materials Science and Technology, vol.8, 1992, p.399-405.

7. Orban,R., Domsa,s., Constantinescu,v. - New composite matrices... with increased wear resistance. Plansee Proceedings, Reute, Austria, 1993, vol.2, p.307-316. 